\title{
MITRAL STENOSIS AND HYPERTENSION
}

\author{
BY \\ IAN R. GRAY \\ From University College Hospital \\ Received April 151953
}

Hypertension is often found in cases of mitral stenosis but reports of the frequency of the association have varied widely. Those who have encountered an unduly high incidence have attempted to establish a causative relationship between the two conditions, but none of the theories put forward have been generally accepted. Opinions of the effect of hypertension on the course of mitral stenosis have been conflicting. A further study of the problem has been made reviewing the incidence of hypertension in 200 cases of mitral stenosis and determining its influence on the disease.

Many years ago granular kidneys were noticed to be common with mitral stenosis (Goodhart, 1880), and Pitt (1887) thought that hypertension from the renal disease might have caused the changes in the mitral valve. When the rheumatic origin of mitral stenosis was accepted the association of hypertension and mitral stenosis was attributed to the co-existence of renal disease and rheumatic heart disease (Cowan and Fleming, 1912). This view was held by Carey Coombs (1924) who pointed to scarlet fever as a likely common source of renal and cardiac involvement. Boas and Fineberg (1926) found hypertension (systolic blood pressure over 150, diastolic blood pressure over $90 \mathrm{~mm}$. $\mathrm{Hg}$ ) in 39 of 135 cases of mitral stenosis. Of patients in this series over the age of 40, 55 per cent had hypertension: in 18 fatal cases they found the presence of granular kidneys was closely related to hypertension and suggested that the hypertension was the result of renal anoxia from a low cardiac output. Levine and Fulton (1928) reported similar findings in 762 cases of mitral stenosis; their series included 159 cases over the age of 45 , of whom 58 per cent were hypertensive. Average blood pressures in cases of mitral stenosis were higher after the third decade than normals taken from life insurance tables. They also drew attention to the high incidence of the association in women and thought that hypertension was beneficial in mitral stenosis, the left ventricular enlargement causing dilatation of the mitral ring, and the systemic hypertension equalizing the burden on the left and right ventricles.

Brumm and Smith (1941) found hypertension in only 2 per cent of their cases of mitral stenosis: and believed that its development worsened the prognosis. Horns (1944) found hypertension in 10 per cent of cases under the age of 45 and 30 per cent over 45 . Roseman and Wasserman (1951) gave similar figures for 517 patients with mitral stenosis whose blood pressures they compared with a series of 2000 consecutive hospital admissions: they found no difference in the incidence of hypertension in the two groups.

Large-scale investigations of the blood pressure with increasing age have shown that an appreciable increase of systolic and diastolic levels is to be expected. In this study a systolic pressure exceeding 150 and a diastolic pressure exceeding $90 \mathrm{~mm}$. $\mathrm{Hg}$ have been taken to constitute hypertension; this facilitates comparison with other reports, but is not necessarily abnormal. Master et al. (1943) found that 50 per cent of men and 62 per cent of women over 50 were hypertensive by these standards. The control series in the present investigation gave appreciably lower figures, possibly because the patients were examined at rest in bed. 
Material. 200 cases of rheumatic heart disease with mitral stenosis without aortic valve involvement were studied. These were patients admitted to the medical wards of University College Hospital between 1947 and 1952. The blood pressure was measured at rest in bed during the first few days after admission in accordance with the method recommended by the Cardiac Society of Great Britain and Ireland (1939). A single reading exceeding 150/90 was disregarded if subsequent levels were lower. In patients admitted on more than one occasion only the latest admission was considered. In most cases of mitral stenosis the blood pressure readings were taken by the author personally. Particular difficulty in measuring the blood pressure accurately was encountered where auricular fibrillation was present: the pressures recorded were the highest systolic and the lowest diastolic levels.

For comparison the records of 200 cases in which uncomplicated peptic ulcer was diagnosed were selected which matched for age and sex the cases of mitral stenosis. These were also in-patients in whom the readings were taken at rest in bed, but in this group the measurements were made by various members of the resident staff.

Cases of mitral stenosis with hypertension were examined clinically and radiographically and electrocardiographic studies made on a number of them. Urine examination and renal function tests were carried out if indicated after congestive failure was no longer present. Autopsy findings in fatal cases were reviewed with particular regard to the heart and kidneys.

Hypertension in Mitral Stenosis and in Controls

The incidence of hypertension in mitral stenosis was 16.5 per cent. Up to the age of 45 , the figure was 8 per cent and over 45 years, 28 per cent. In Table I these figures are compared with those reported elsewhere.

TABLE I

InCidence of Hypertension in Cases of Mitral Stenosis

\begin{tabular}{|c|c|c|c|}
\hline & $\begin{array}{c}\text { All ages } \\
(\%)\end{array}$ & $\begin{array}{c}\text { Over } 45 \\
(\%)\end{array}$ & $\begin{array}{c}\text { Under } 45 \\
(\%)\end{array}$ \\
\hline 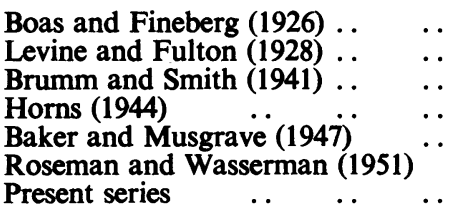 & $\begin{array}{l}\frac{29}{2} \\
\frac{24}{20} \\
17\end{array}$ & $\begin{array}{l}55^{*} \\
58 \\
\frac{30}{30 \dagger} \\
32 \\
28\end{array}$ & $\frac{7}{\frac{7}{13}}$ \\
\hline
\end{tabular}

* Over 40 years of age. † Over 50 years of age.

TABLE II

inCidence of Hypertension in 200 Cases of Mitral Stenosis and in 200 Controls

\begin{tabular}{|c|c|c|c|c|c|}
\hline \multirow[b]{3}{*}{$\begin{array}{l}\text { Mitral } \\
\text { stenosis .. } \\
\text { Controls .. }\end{array}$} & \multirow[b]{2}{*}{$\begin{array}{l}\text { Overall } \\
\text { incidence } \\
(200)\end{array}$} & \multicolumn{2}{|c|}{ Women } & \multicolumn{2}{|c|}{ Men } \\
\hline & & $\begin{array}{c}45 \text { years } \\
\text { and under } \\
(83)\end{array}$ & $\begin{array}{c}\text { Over } 45 \\
\text { (73) }\end{array}$ & $\begin{array}{l}45 \text { years } \\
\text { and under } \\
(30)\end{array}$ & $\begin{array}{c}\text { Over } 45 \\
\text { (14) }\end{array}$ \\
\hline & $\begin{array}{l}16.5 \% \text { (33) } \\
11.0 \% \text { (22) }\end{array}$ & $\begin{array}{l}9 \cdot 6 \% \text { (8) } \\
6.0 \% \text { (5) }\end{array}$ & $\begin{array}{l}28.7 \%(21) \\
19.0 \%(14)\end{array}$ & $\begin{array}{l}3 \cdot 3 \%(1) \\
3 \cdot 3 \%(1)\end{array}$ & $\begin{array}{l}21 \cdot 5 \%(3) \\
14 \cdot 2 \%(2)\end{array}$ \\
\hline
\end{tabular}

Figures in brackets are the actual numbers of cases.

In Table II the incidence of hypertension is compared with that found in 200 cases of peptic ulcer of the same age and sex. These figures demonstrate the anticipated higher incidence of hypertension in the older age group and in women. The incidence of hypertension is also slightly higher among cases of mitral stenosis than among controls in all age and sex groups. The differences, however, are not statistically significant. 
Average systolic and diastolic pressures were calculated for each group divided into 5-year age periods. Because of the smaller numbers all those under 25 years old and all those over 60 were grouped together. A graph was prepared (Fig. 1) which is comparable with that of Levine and Fulton (1928). Between the ages of 40 and 60 the average systolic blood pressure in cases of mitral stenosis was found to be $10 \mathrm{~mm}$. higher, and the diastolic level $5 \mathrm{~mm}$. higher, than in the controls. Above 60 years of age the average systolic and diastolic levels were higher in the controls.

\section{Clinical Features of Mitral Stenosis with Hypertension}

The mitral stenosis in cases with hypertension has been thought to be less severe than in those with a normal or low blood pressure (Brumm and Smith, 1941), and it is true that the most severe cases of mitral stenosis die from congestive failure or rheumatic fever before they are old enough for hypertension to develop. The clinical and pathological severity of the mitral stenosis in cases who reached middle-age was, however, no different in those with high and in those with normal blood pressure. In this series advanced disease was usual and congestive failure frequent. Even allowing for age, auricular fibrillation was found to be more frequent in those with a raised pressure (91 per cent over 45 years old, compared with 78 per cent).

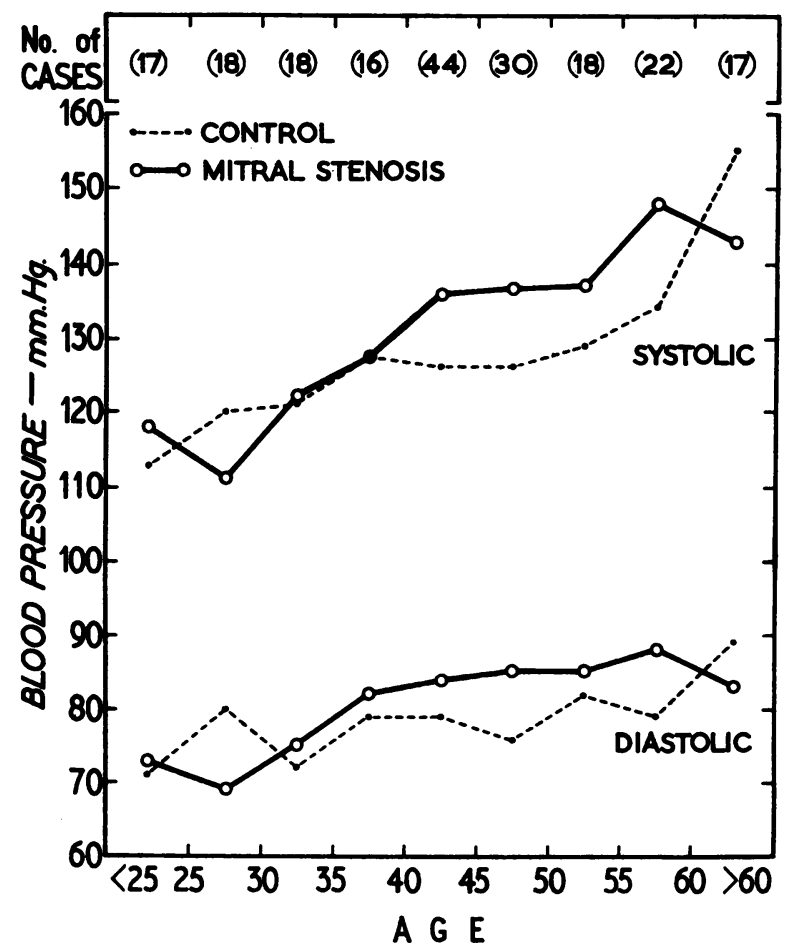

Fig. 1.-Average blood pressure at different ages in 200 cases of mitral stenosis and 200 controls.

Hypertension usually modified the cardiac signs. The left ventricle was hypertrophied and the apex beat was forceful and was displaced to the left. In the absence of aortic valve disease or mitral regurgitation this could be attributed to the hypertension. Retinal changes were common and sometimes severe. Although coronary artery disease with angina of effort or myocardial infarction has been observed in cases of mitral stenosis (Wartman and Hellerstein, 1948; Chasnoff and Silver, 1951), it was not recognized clinically in this series. This complication might be expected to occur more frequently with hypertension.

Electrocardiograms frequently showed the pattern of left ventricular hypertrophy usually 
in leads V6 and V7. Depression of S-T segments over the left ventricle was common but this was frequently attributable to digitalis. A large left ventricle could usually be recognized on fluoroscopy.

There was no evidence to support the belief of Levine and Fulton (1928) that cardiac function is improved by hypertension. In 8 cases developing hypertension while attending hospital there was already severe cardiac disease with considerable disability and no appreciable change in the exercise tolerance took place. Renal failure was a significant feature in only two cases.

Hypertension was generally an incidental finding of no great consequence. In a small group, however, symptoms and signs of hypertension dominated the clinical picture and even determined a fatal outcome. The following case reports illustrate this.

\section{Cases with Severe Hypertension}

Severe Hypertensive Symptoms. The patient was a stoker, aged 56, who complained of severe occipital headaches and dyspnoa on effort for one year. His blood pressure was 175/110 and grade 2 hypertensive retinopathy was present. The heart was large with a big left ventricle. There were signs of mitral stenosis and auricular fibrillation, and the cardiogram showed left ventricular strain. Five months later he developed congestive failure. His blood pressure was 230/140, severe headaches persisted, and soon after, a transient left hemiplegia occurred. He was treated with hexamethonium with striking relief of headaches and considerable fall of blood pressure. He died from congestive failure and pulmonary embolism. Autopsy showed much hypertrophy of the left ventricle and dilatation of the left atrium. The mitral valve was greatly narrowed and scarred. The coronary arteries were atheromatous. The kidneys were granular and there was considerable thickening of the renal arteries and arterioles.

Malignant Hypertension. The patient is a housewife, who was treated for congestive failure at the age of 33 when signs of mitral stenosis and auricular fibrillation were found. At 46 she noticed severe headaches and deteriorating vision. A blood pressure of 198/114 and bilateral papilloedema with retinal hæmorrhages and exudates were found. Blood urea was $60 \mathrm{mg}$. per $100 \mathrm{ml}$. There was much cardiac enlargment affecting the left atrium and ventricle, and a loud low-pitched diastolic murmur and a short blowing systolic murmur at the apex. The cardiogram showed a vertical heart with clockwise rotation and left ventricular strain. Treatment with hexamethonium has achieved some fall in blood pressure and relief of headaches.

Hypertension and Cerebral Hamorrhage. This patient was a housewife of 55 who was known to have had " heart trouble " for some years, and two years before had been found to be hypertensive. She was admitted, having suddenly lost consciousness with signs of a spastic tetraplegia. The blood pressure was 190/110. The heart was enlarged with a rumbling diastolic and a blowing systolic murmur at the apex. The cardiogram showed auricular fibrillation with a semi-vertical heart with clockwise rotation. Her condition deteriorated and hypertension continued, the highest reading being $235 / 180$. She died after 48 hours. Autopsy showed severe mitral stenosis with considerable hypertrophy of both ventricles. The kidneys were slightly granular with arteriolosclerotic changes. There was an extensive cerebral hæmorrhage involving the left internal capsule.

Severe Hypertension with Multiple Renal Infarcts. This lady had been an acrobat and was known to have mitral stenosis and auricular fibrillation. Right nephrectomy was carried out for a massive infarction of the right kidney, the blood pressure at this time being 125/60. A year later she complained of deteriorating vision from a severe grade 3 hypertensive retinopathy, and of bouts of pain in the left loin. The blood pressure had risen to 230/120. Finally, she developed a constant pain in the left loin and anuria from which she died. Autopsy showed severe mitral stenosis with hypertrophy of both ventricles. There was thrombosis of the abdominal aorta and recent complete infarction of the left kidney. In addition, four older renal infarcts were present. Microscopy showed severe arteriosclerosis and arteriolosclerosis of the renal vessels.

\section{Prognosis in Mitral Stenosis with Hypertension}

Thirty-eight of the 200 cases of mitral stenosis died during the period of survey. Eleven had hypertension and in 27 the blood pressure was normal. The average age at death of the cases with hypertension was $52(38-67)$ years. The average figure for the cases without hypertension was $46(20-74)$ years. Since this latter group contained a number who died before the age of risk of hypertension the figures are not comparable. If cases dying before the age of 45 are excluded the 
average figure is 55 for both groups. This suggests that no appreciable change in life expectancy is to be expected when hypertension is present. In most cases hypertension seemed to have no effect on the course of mitral stenosis. In a small number severe hypertension added to the disability and even caused death.

\section{Pathology in Mitral Stenosis with Hypertension}

Autopsy was carried out in 10 of the 11 fatal cases of mitral stenosis with hypertension. In 9 there was hypertrophy of the left ventricle and in 3 this was considerable. In a group of fatal cases of mitral stenosis without hypertension of about the same age, left ventricular hypertrophy of slight degree was present in about half. No difference in the severity of the mitral stenosis could be detected in the two groups. Coronary atheroma was found in 3 of the 10 cases, the same incidence as in those with normal pressures.

The kidneys were entirely normal on macroscopic and microscopic examination in only two cases. Multiple renal infarcts were found four times and the kidneys were granular although not greatly contracted in four. Microscopy showed arteriosclerosis in six and arteriolosclerosis in two cases. The incidence of infarction, granular kidneys, and arteriosclerosis was no different in the cases of mitral stenosis without hypertension but arteriolosclerosis was never found. No cases of chronic nephritis or of grossly contracted kidney were encountered.

The two cases with arteriolosclerosis were both examples of severe hypertension (Cases 3 and 4). One was apparently an essential hypertension while the other, where repeated infarction of the remaining kidney after nephrectomy was attended by the development of severe hypertension, was possibly an example of renal hypertension. Hypertension following renal infarction was recently reviewed by Wainwright (1949) who collected eight reported cases as well as describing a further example.

\section{Discussion}

This study has confirmed that hypertension is found in a considerable proportion of patients with mitral stenosis who reach middle age. Although the difference is not statistically significant there is a suggestion that blood pressures are higher than in normal controls. The pathological findings in fatal cases give no support to an anatomically recognizable renal cause for the hypertension. No case of chronic nephritis was encountered and if renal infarction can cause hypertension it probably does so rarely. The age and sex incidence is that of essential hypertension and this must be accepted as the most likely cause in most cases.

In none of the 33 cases of mitral stenosis in which hypertension was found was any improvement in cardiac function attributable to it. The prognosis for life was much the same as in other cases of mitral stenosis of the same age. Severe hypertension added fresh symptoms and worsened the patients' condition and renal and cerebro-vascular complications sometimes dominated the clinical picture. In the majority, however, hypertension was an incidental finding having no influence on the course of the illness.

\section{SUMMARY}

The blood pressure exceeded 150/90 mm. $\mathrm{Hg}$ in 33 of 200 cases of mitral stenosis. This incidence of 16.5 per cent was not significantly higher than in 200 control cases of the same sex and age.

Hypertension in mitral stenosis is an essential hypertension in nearly all cases, and a renal origin is uncommon. The clinical and electrocardiographic signs in mitral stenosis are modified by left ventricular hypertrophy when hypertension is present.

Hypertension in no way improves the prognosis when it develops in a case of mitral stenosis. Occasionally it causes additional disability and may contribute to a fatal outcome.

I have much pleasure in thanking the physicians of University College Hospital for allowing me access to their patients and to their records, and particularly to Professor M. L. Rosenheim and Dr. K. E. Harris who read and criticized this paper. I am also indebted to Dr. John Knoweldon for statistical advice and to Mr. V. K. Asta who prepared the graph. 


\section{REFERENCES}

Boas, E. P., and Fineberg, M. H. (1926). Amer. J. med. Sci., 172, 648.

Brumm, H. J., and Smith, H. L. (1941). Minn. Med., 24, 664.

Chasnoff, J., and Silver, A. (1951). Amer. Heart J., 42, 809.

Coombs, Carey F. (1924). Rheumatic Heart Disease. Bristol.

Cowan, J., and Fleming, G. B. (1912). Quart. J. Med., 5, 309.

Goodhart, J. F. (1880). Lancet, 1, 479.

Horns, H. L. (1944). Amer. Heart J., 28, 435.

Levine, S. A., and Fulton, M. N. (1928). Amer. J. med. Sci., 176, 465.

Master, A. M., Marks, H. H., and Dack, S. (1943). J. Amer. med. Ass., 121, 1251.

Pitt, G. N. (1887). Brit. med. J., 2, 118.

Roseman, M. D., and Wasserman, E. (1951). New Engl. J. Med., 245, 450.

Wainwright, J. (1949). Lancet, 1, 62.

Wartman, W. B., and Hellerstein, H. K. (1948). Ann. intern. Med., 28, 41.

Joint Report of Committees of Cardiac Society of Great Britain and Ireland and American Heart Association (1939). Brit. med. J., 2, 184. 